\title{
One-step removal of lead from water using an electricity-free and sustainable membrane filtration
}

\author{
Junwei Zhang ${ }^{*}$, Yan Tung Lo, Hao Guo and Chuyang Tang \\ Department of Civil Engineering, The University of Hong Kong, Hong Kong, People's Republic of China
}

\begin{abstract}
Lead $(\mathrm{Pb})$ is a typical contaminant in water with adverse effects on human health. Hong Kong's incident of drinking water contamination by $\mathrm{Pb}$ in 2015 caused severe public concerns regarding drinking water safety. Conventional treatment methods for $\mathrm{Pb}$ removal generally require electricity, chemical dosage, and considerable time and space, which significantly restrict their use for rapid water purification under emergency situations. In this study, a polyvinyl alcohol/ polyacrylic acid (PVA/PAA) composite nanofibrous membrane was developed for the rapid and effective removal of $\mathrm{Pb}$ from water. The PVA/PAA membrane had a high water permeability of $550 \mathrm{~L} / \mathrm{m}^{2} / \mathrm{h} / \mathrm{kPa}-710 \mathrm{~L} / \mathrm{m}^{2} / \mathrm{h} / \mathrm{kPa}$, which allowed the filtration to be driven by gravity (e.g. with a water height of $10.0 \mathrm{~cm}$ ). The membrane showed consistently high removal efficiency of $\mathrm{Pb}(>95 \%)$ with a volumetric loading up to $3000 \mathrm{~L} / \mathrm{m}^{2}$. This high removal efficiency was attributed to the combined effects of complexing and electrostatic attraction between $\mathrm{Pb}$ and PAA. An esculent citric acid was used to regenerate the exhausted PVA/PAA membrane. The regenerated membrane maintained its removal efficiency of $\mathrm{Pb}$ over a five-cycle filtration. These results imply that the PVA/PAA composite membrane can be repeatedly used in electricity-free filtration devices for rapid elimination of $\mathrm{Pb}$ under emergency situations.
\end{abstract}

KEYWORDS Lead; drinking water; nanofibrous membrane; filtration; electricity-free; removal efficiency; regeneration CONTACT Junwei ZHANG@ junwei17@connect.hku.hk

Received 26 March 2020

\section{Introduction}

Reliable and safe drinking water is vital for a modern society. World Health Organisation (WHO) reported that in 2017 , almost $30 \%$ of the global population was encountering drinking water contamination and close to half a million death per year was caused by contaminated drinking water (World Health Organisation, 2019). Heavy metals are typical contaminants in drinking water with significant toxicity to human health (Chowdhury et al., 2016). Therefore, WHO has established rigorous standards to regulate the concentration level of heavy metals in drinking water (World Health Organisation, 2011). For example, the guideline concentration of lead $(\mathrm{Pb})$ is $10 \mu \mathrm{g} / \mathrm{L}$. However, actual $\mathrm{Pb}$ concentration may go high over $100 \mu \mathrm{g} / \mathrm{L}$ when $\mathrm{Pb}$-contained components are used in the water supply system (Gonzalez et al., 2013; World Health Organisation, 2011). An incident of drinking water contamination by $\mathrm{Pb}$ occurred in Hong Kong in 2015 (HKSAR Government, 2015) where the Pb concentration in tap water greatly exceeded the WHO standard. Due to the severe threats of $\mathrm{Pb}$ to public health (Papanikolaou et al., 2005), effective strategies for rapid removal of $\mathrm{Pb}$ are required to produce safe drinking water under such emergency situations.

Various approaches have been investigated to treat $\mathrm{Pb}$ contamination ( $\mathrm{Fu}$ and Wang, 2011), such as chemical precipitation (Matlock et al., 2002), adsorption (Babel and Kurniawan, 2003), ion exchange (Guo et al.,
2013), membrane filtration (Mehdipour et al., 2015), and electrochemical treatment (Liu et al., 2013). Although these methods could achieve an effective removal of $\mathrm{Pb}$, they generally require electricity, chemical dosage, and/or considerable space and time. Due to these constraints, these conventional methods may not be suitable for situations that require instant and highly-mobile water production, such as rapid provision of safe drinking water for chemical leakage incidents. An ideal treatment technology for such emergency situations should be electricity-free, chemicalfree, compact, and highly efficient with the ability to remove contaminants instantaneously.

Gravity-driven membrane filtration is a technique using gravity to drive water permeating across a membrane (Pronk et al., 2019). It has been used in different scenarios of decentralised water treatment thanks to its simple, mobile, and electricity-free operation (Derlon et al., 2012; Oka et al., 2017; Peter-Varbanets et al., 2010). The existing gravity-driven membrane filtrations mainly rely on microfiltration (MF) and ultrafiltration (UF), which can retain microorganisms and suspended solids (Pronk et al., 2019). However, they are generally not effective to remove dissolved contaminants such as heavy metals due to the small sizes of the contaminants. Nanofibrous membrane is a type of highly porous membrane consisting of numerous nanofibres fabricated by electrospinning (Ahmed et al., 2015). The large porosity allows the membrane to be driven by gravity (Guo et al., 2017; Wang et al., 2017a; Wang et al., 2017b). Meanwhile, its great internal area provides 
abundant sites for functional groups to capture the targeted contaminants (Aliabadi et al., 2013; Kampalanonwat and Supaphol, 2010).

In the current study, a highly porous and functionalised nanofibrous membrane using water soluble polyvinyl alcohol (PVA) and polyacrylic acid (PAA) was fabricated to achieve one-step rapid removal of $\mathrm{Pb}$ from water. The membrane filtration behaviours including water permeability and removal efficiency of $\mathrm{Pb}$ were systematically investigated under a gravitydriven condition. A simple citric acid wash was developed to in-situ regenerate the exhausted membrane to allow its sustainable reuse. The findings may inspire the development of novel membrane filter products for rapid water purification in emergency and disaster relief.

\section{Materials and methods}

\subsection{Chemicals}

Lead nitrate $\left(\mathrm{Pb}\left(\mathrm{NO}_{3}\right)_{2}, \geq 98.5 \%\right.$, VWR) was used as the source of $\mathrm{Pb}$. PVA (molecular weight of $\sim 74800, \mathrm{TCI}$ ) and PAA (50 wt.\% water solution, Acros Organics) were used to fabricate the PVA/PAA composite nanofibrous membrane via electrospinning. Acetic acid (RCI Labscan), glutaraldehyde (24-26 wt.\% water solution, Dieckmann), and hydrochloric acid (37\%, VWR) were used to crosslink the PVA/PAA membrane. Citric acid (Dieckmann) was used to prepare the regeneration solution for membrane reuse.

\subsection{PVA/PAA membrane fabrication}

The polymer solution was prepared by dissolving PVA and PAA with desired amount in water at a $90^{\circ} \mathrm{C}$ water bath overnight. The PVA content was fixed at $10 \mathrm{wt} . \%$ and the PAA content was 0,1 , and $10 \mathrm{wt} . \%$, with the corresponding membranes named as PVA, PVA/PAA1, and PVA/PAA10, respectively. The prepared solution was then taken out of the water bath and cooled down to room temperature before further using. An electrospinning machine (ET-2535, Ucalery) was used to fabricate the PVA/PAA nanofibrous membrane. A $30 \mathrm{~mL}$ polymer solution was evenly loaded into three spinnerets used for electrospinning. The fabrication parameters were: a polymer injection rate of $0.03 \mathrm{~mm} /$ minute, a voltage of $22 \mathrm{kV}$, and a collection distance (from the top of spinneret to the collect roll) of $15 \mathrm{~cm}$. The electrospun nanofibrous membrane was then carefully peeled off from the collector and immersed in a crosslinking solution consisting of $96 \mathrm{~mL}$ acetic acid, $4 \mathrm{~mL}$ glutaraldehyde, and $0.1 \mathrm{~mL}$ hydrochloric acid for 30 minutes. The crosslinked membrane was thoroughly rinsed with and stored in Milli-Q water.

\subsection{Membrane characterisation}

The morphology and structure of the nanofibrous membrane were characterised by a field emission scanning electron microscope (FE-SEM, S-4800, Hitachi). A sputter coater (SCD 005, Bal-tecTM) was used to coat a thin layer of gold on the membrane sample before SEM characterisation. Functional groups in the nanofibrous membrane were analysed by a Fourier transform infrared spectrometer (FTIR, Nicolet iS5, Thermo Scientific) equipped with an attenuated total reflection (ATR, iD5, Thermo Scientific). All membrane samples used for SEM and FTIR characterisation were freeze-dried in advance. Membrane porosity $(\varepsilon)$ was measured using a weight method (Wang et al., 2017b):

$$
\varepsilon=\frac{\left(W_{w e t}-W_{d r y}\right) / \rho_{w}}{\left(\frac{W_{w e t}-W_{d r y}}{\rho_{w}}\right)-\left(W_{d r y} / \rho_{p}\right)} \times 100 \%
$$

where $W_{w e t}$ and $W_{d r y}$ are the weight of the wet and dry membrane samples, respectively; $\rho_{w}$ and $\rho_{p}$ are the density of water and polymer, respectively. The reported porosity data were acquired from at least three parallel tests.

\subsection{Filtration experiments}

A gravity-driven filtration cell modified from our previous study was used to perform the filtration experiments (Guo et al., 2017). Briefly, a membrane coupon was packed in the cell with an effective filtration area of $3.5 \mathrm{~cm}^{2}$. Approximately $50 \mathrm{~mL}$ water was added into the cell to rinse the membrane first. Subsequently, a feed solution containing $200 \mu \mathrm{g} / \mathrm{L} \mathrm{Pb}$ was continuously pumped into the cell by a micro-peristaltic pump (BT100-2J, Longer Pump). The water height was maintained at 10.0 $\mathrm{cm}$ (equivalent pressure of $0.98 \mathrm{kPa}$ ) by adjusting the pump rate. Permeate samples were collected at predetermined volume intervals. The water permeability was calculated using following equations:

$$
\begin{aligned}
& J_{w}=\frac{\Delta m / \rho_{w}}{A r \cdot t}, \\
& A=\frac{J_{w}}{\Delta P},
\end{aligned}
$$

where $J_{w}$ is water flux, $\Delta m$ is the collected mass of permeate (measured by a digital balance), $A_{r}$ is the effective filtration area, $t$ is the collection time, $A$ is water permeability, and $\Delta P$ is the applied pressure.

The concentration of $\mathrm{Pb}$ was determined by an inductively coupled plasma mass spectrometry (ICP-MS, Agilent 7900). The instrumental detection limit of $\mathrm{Pb}$ was $0.05 \mu \mathrm{g} / \mathrm{L}$ (Appendix A). The removal efficiency of heavy metal was calculated by: 


$$
R=\left(1-\frac{C_{p}}{C_{f}}\right) \times 100 \%,
$$

where $R$ is the removal efficiency, $C_{p}$ and $C_{f}$ are the $\mathrm{Pb}$ concentration of permeate and feed samples, respectively. All the filtration experiments were triplicated.

\subsection{Membrane regeneration}

To ensure a sustainable reuse of the nanofibrous membrane, a simple citric acid wash was adopted to regenerate the exhausted membrane (e.g. PVA/PAA1). After the completion of initial filtration for $\mathrm{Pb}$ solution, a $50 \mathrm{~mL} 1 \mathrm{M}$ citric acid solution was introduced to the filtration cell to in-situ regenerate the membrane. The regenerated membrane was then rinsed by ultrapure water. After the rinsing, a new cycle of $\mathrm{Pb}$ filtration experiment was conducted (under identical test conditions of the initial cycle). The filtration/regeneration experiment was repeated for a total of five cycles.

\section{Results and discussion}

\subsection{Membrane characterisation}

(a)

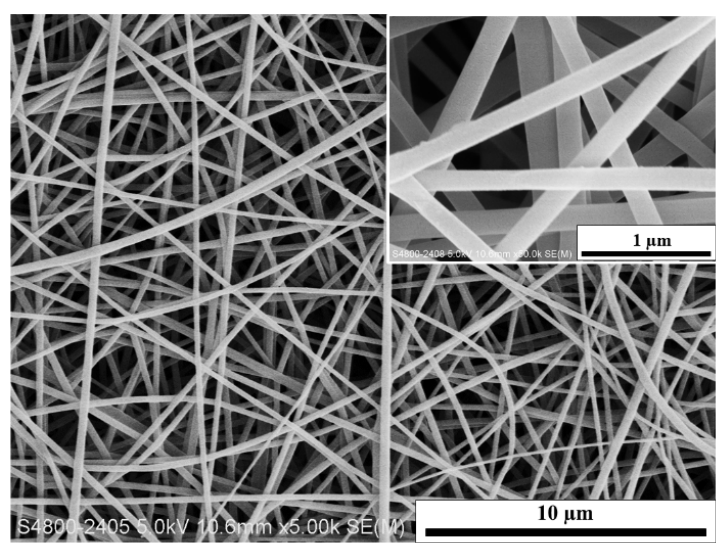

(b)

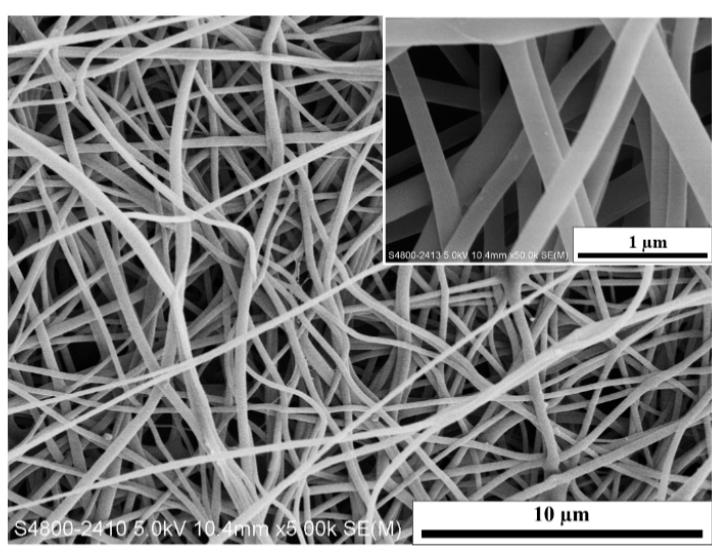

(c)

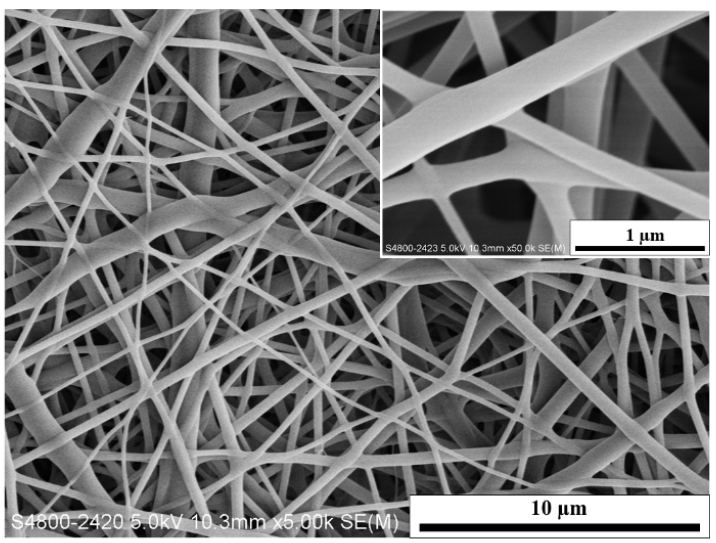

Figure 1. SEM micrographs of nanofibrous membranes of (a) PVA; (b) PVA/PAA1; and (c) PVA/PAA10. Insets were used to show the micrographs with a higher magnification. All the micrographs were acquired at an acceleration voltage of $5.0 \mathrm{kV}$.

The morphology and structure of PVA, PVA/PAA1, and PVA/PAA10 nanofibrous membranes are presented in Figure 1. All the membranes showed the typical reticulate appearance consisting of numerous nanofibres (Wang and Hsiao, 2016). The nanofibre diameter of the pure PVA membrane ranged generally from $100 \mathrm{~nm}$ to $200 \mathrm{~nm}$ (Figure 1(a)). With the incorporation of PAA into the nanofibrous membranes, the distribution of nanofibre diameters was broadened (Figures 1(b) and 1(c)). With a high PAA content of $10 \%$ (see PVA/PAA10 in Figure 1(c)), larger-diameter nanofibres of several hundred nanometers were more frequently observed. In addition, this membrane appeared to have less open area than the pure PVA membrane, indicating a reduction in its porosity.

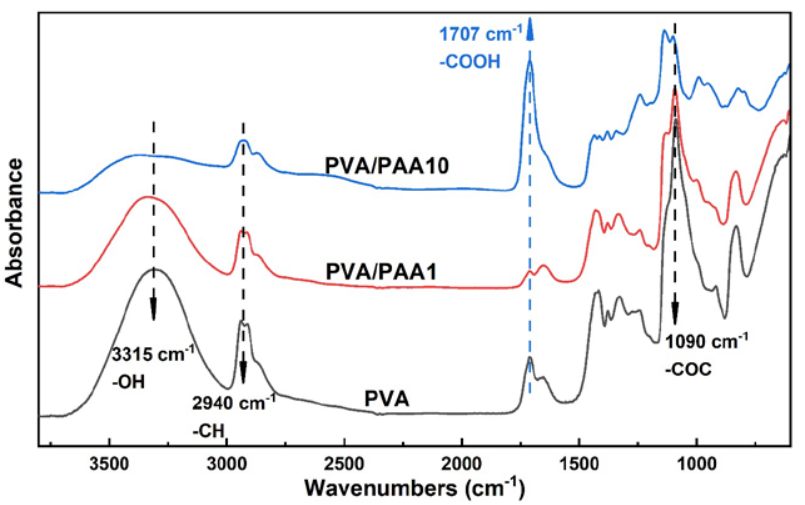

Figure 2. ATR-FTIR spectra of PVA, PVA/PAA1, and PVA/ PAA10 nanofibrous membranes.

Figure 2 presents the characterisation of functional groups of the membranes by ATR-FTIR. The PVA membrane showed characteristic peaks at $1090 \mathrm{~cm}^{-1}$, 
$2940 \mathrm{~cm}^{-1}$, and $3315 \mathrm{~cm}^{-1}$, which are assigned to functional groups of -COC, $-\mathrm{CH}$, and $-\mathrm{OH}$ of the polymer, respectively (Hyder et al., 2006; Mansur et al., 2008). The inclusion of PAA in the PVA/PAA1 and PVA/PAA10 membranes significantly weakened these peaks due to the dilution of the PVA content. On the other hand, the peak at $1707 \mathrm{~cm}^{-1}$, corresponding to carboxylic groups - $\mathrm{COOH}$ (Kirwan et al., 2003), became intense for the PVA/PAA10 membrane due to the high concentration of - $\mathrm{COOH}$ groups contained in its PAA polymer.

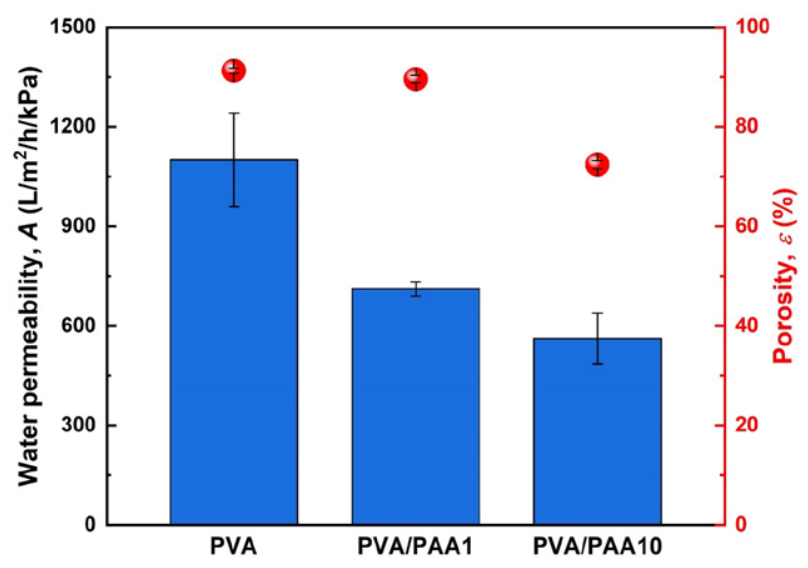

Figure 3. Water permeability (bars) and porosity (circles) of PVA, PVA/PAA1, and PVA/PAA10 nanofibrous membranes. Water permeability was measured at a water height of $10.0 \mathrm{~cm}$ (i.e. $0.98 \mathrm{kPa}$ ).

Membrane water permeability and porosity are shown in Figure 3. The water permeability of the nanofibrous membranes ranged from $550 \mathrm{~L} / \mathrm{m}^{2} / \mathrm{h} / \mathrm{kPa}$ to $1100 \mathrm{~L} / \mathrm{m}^{2} /$ $\mathrm{h} / \mathrm{kPa}$, which is $3-4$ orders of magnitude higher than the value for conventional UF membranes (e.g. $0.2 \mathrm{~L} / \mathrm{m}^{2} / \mathrm{h} / \mathrm{kPa}$ - $5 \mathrm{~L} / \mathrm{m}^{2} / \mathrm{h} / \mathrm{kPa}$ ) used in gravity-driven membrane filtration (Fane et al., 2011; Pronk et al., 2019). Such a high water permeability allows a much more rapid water purification and greatly reduces the required water head $(10.0 \mathrm{~cm}$ in this study vs $0.4 \mathrm{~m}-1.0 \mathrm{~m}$ in conventional membranes). Compared with the pure PVA nanofibrous membrane, the PVA/PAA composite nanofibrous membranes showed a reduced water permeability, which may be attributed to the decreased membrane porosity (e.g. 91\% for PVA membrane and $72 \%$ for PVA/PAA10 membrane). This result suggests that an overloading of PAA in the composite nanofibrous membrane may compromise the membrane porosity and water permeability.

\subsection{Lead removal performance}

(a)

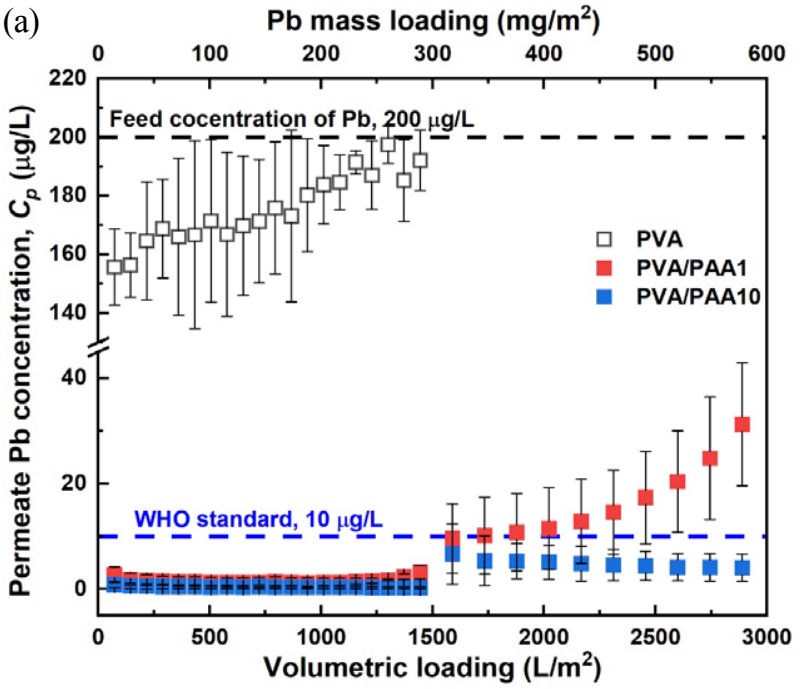

(b)

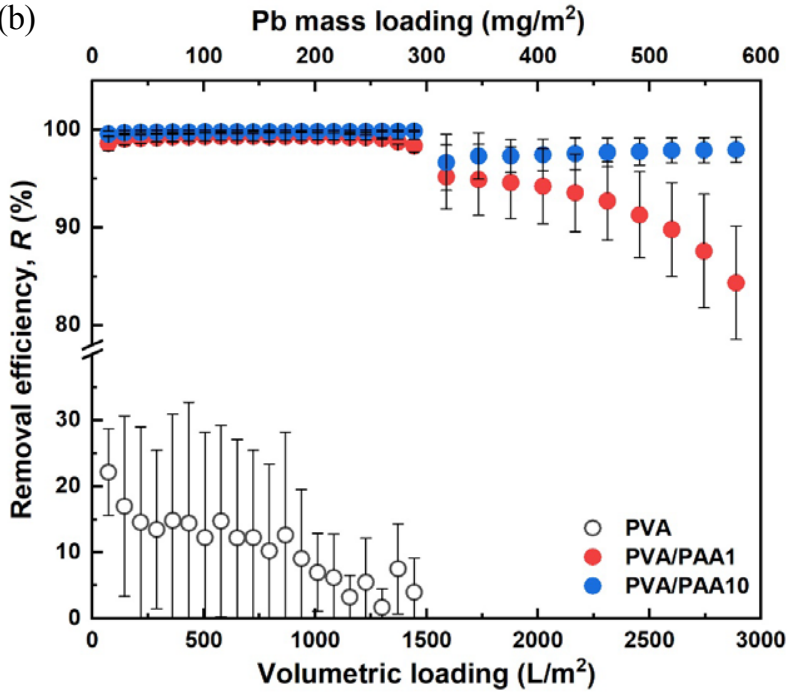

Figure 4. (a) The $\mathrm{Pb}$ concentration in the permeate samples $\left(C_{p}\right)$ and (b) Pb removal efficiency $(R)$ of PVA, PVA/PAA1, and PVA/PAA10 nanofibrous membranes at different volumetric and $\mathrm{Pb}$ mass loadings. The feed concentration of $\mathrm{Pb}$ was $200 \mu \mathrm{g} / \mathrm{L}$. The volumetric loading represents the volume of the treated solution normalised by the effective filtration area, and $\mathrm{Pb}$ mass loading is calculated as the product of $\mathrm{Pb}$ concentration in the feed water $(200 \mu \mathrm{g} / \mathrm{L})$ and the volumetric loading.

To determine the $\mathrm{Pb}$ removal performance, a feed solution containing $200 \mu \mathrm{g} / \mathrm{L} \mathrm{Pb}$ was filtrated by PVA, PVA/PAA1, and PVA/PAA10 nanofibrous membranes under gravity (i.e. water height of $10.0 \mathrm{~cm}$ ). The $\mathrm{Pb}$ concentration in permeate samples for the three membranes are presented in Figure 4(a). The corresponding $\mathrm{Pb}$ removal efficiency is shown in Figure 4(b). Compared to the pure PVA membrane, the PVA/PAA composite membranes showed a significantly lower permeate $\mathrm{Pb}$ concentration 
and higher removal efficiency. The $\mathrm{Pb}$ concentration in the permeate sample of the pure PVA nanofibrous membrane consistently exceeded $150 \mu \mathrm{g} / \mathrm{L}$ (corresponding to the removal efficiency of less than $25 \%$ ), implying a weak retention of $\mathrm{Pb}$ by PVA alone. In contrast, both PVA/ PAA1 and PVA/PAA10 membranes resulted in permeate $\mathrm{Pb}$ concentrations significantly lower than the WHO standard for drinking water $(10 \mu \mathrm{g} / \mathrm{L})$ up to a volumetric loading of $1500 \mathrm{~L} / \mathrm{m}^{2}$ (i.e. $\mathrm{Pb}$ mass loading of $300 \mathrm{mg}$ / $\mathrm{m}^{2}$ ). The efficient removal of $\mathrm{Pb}$ by these membranes can be attributed to their PAA content. The negatively charged carboxylic groups could capture the positively charged $\mathrm{Pb}^{2+}$ ions thanks to the combined effects of complexing and electrostatic attraction ( $\mathrm{Li}$ and Bai, 2006). Upon further increasing the volumetric loading to $3000 \mathrm{~L} / \mathrm{m}^{2}$, the PVA/ PAA1 membrane experienced a breakthrough behaviour with a dramatically increased permeate $\mathrm{Pb}$ concentration, indicating that its sorption sites had been saturated. In comparison, the permeate $\mathrm{Pb}$ concentration remained below $10 \mu \mathrm{g} / \mathrm{L}$ and the corresponding removal efficiency remained above $95 \%$ for the PVA/PAA 10 membrane due to the much higher PAA content in this membrane.

\subsection{Membrane regeneration}

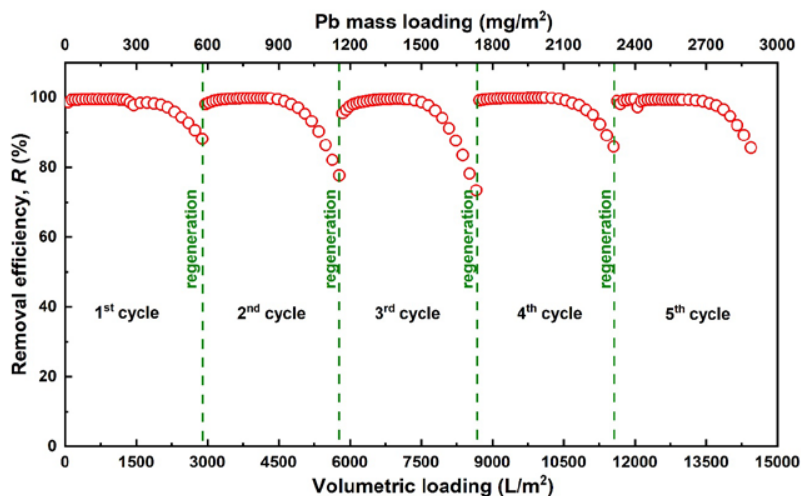

Figure 5. $\mathrm{Pb}$ removal efficiency over five filtrationregeneration cycles by the PVA/PAA1 membrane. During each cycle, the $\mathrm{Pb}$ concentration in the feed solution was maintained at $200 \mu \mathrm{g} / \mathrm{L}$ and the filtration volume was $1 \mathrm{~L}$. All filtration cycles were performed at a water height of $10.0 \mathrm{~cm}$

To ensure the sustainable reuse of the membrane, a simple and effective regeneration method is required. Acid solutions such as $\mathrm{HNO}_{3}$ and $\mathrm{H}_{3} \mathrm{PO}_{4}$ have been reported to desorb $\mathrm{Pb}$ from the adsorbent ( $\mathrm{Li}$ and Bai, 2006). However, these acids are either highly corrosive or oxidative, which are not ideal due to potential safety concerns (particularly for household use scenarios). Since the $\mathrm{Pb}$ capture by the PVA/PAA composite nanofibrous membrane mainly depends on the interactions between $\mathrm{Pb}$ and carboxyl groups (-COOH) in PAA, a carboxyl group-based acid may be a promising regeneration agent. In the current study, a natural and esculent citric acid was used to regenerate the exhausted PVA/PAA1 membrane (Figure 5). Compared to the initial filtration cycle, the overall $\mathrm{Pb}$ removal efficiency by the regenerated membrane maintained well for additional cycles, demonstrating the highly efficient regeneration by citric acid wash. The test further verified the robust property of the PVA/PAA nanofibrous membrane against a long-term usage. For each cycle, a total volume of $1 \mathrm{~L}$ solution was filtrated while only $50 \mathrm{~mL}$ citric acid solution was enough to regenerate the membrane, which could concentrate $\mathrm{Pb}$ in a small volume solution for further beneficial recovery.

\section{Conclusion}

In the current study, a PVA/PAA composite nanofibrous membrane was developed to conduct an electricity-free and sustainable filtration to remove $\mathrm{Pb}$ for rapid water purification. The fabricated PVA/PAA nanofibrous membranes had a typical reticulate structure consisting of numerous nanofibres as confirmed by SEM. ATR-FTIR analysis confirmed the successful incorporation of PAA. The PVA/PAA membranes had a high water permeability of $550 \mathrm{~L} / \mathrm{m}^{2} / \mathrm{h} / \mathrm{kPa}-710 \mathrm{~L} / \mathrm{m}^{2} / \mathrm{h} / \mathrm{kPa}$ together with a porosity of $72 \%-90 \%$. These features enabled the membrane to be operated under gravity (e.g. water height of $10.0 \mathrm{~cm}$ ). The filtration experiments revealed the critical role of PAA for the effective removal of $\mathrm{Pb}$, with the permeate $\mathrm{Pb}$ concentration of the PVA/PAA membranes consistently stood below the WHO standard of $10 \mu \mathrm{g} / \mathrm{L}$ up to a volumetric loading of $3000 \mathrm{~L} / \mathrm{m}^{2}$. The used membrane was successfully regenerated by a simple citric acid wash, which enabled its sustainable reuse.

\section{Appendix A. ICP-MS calibration}

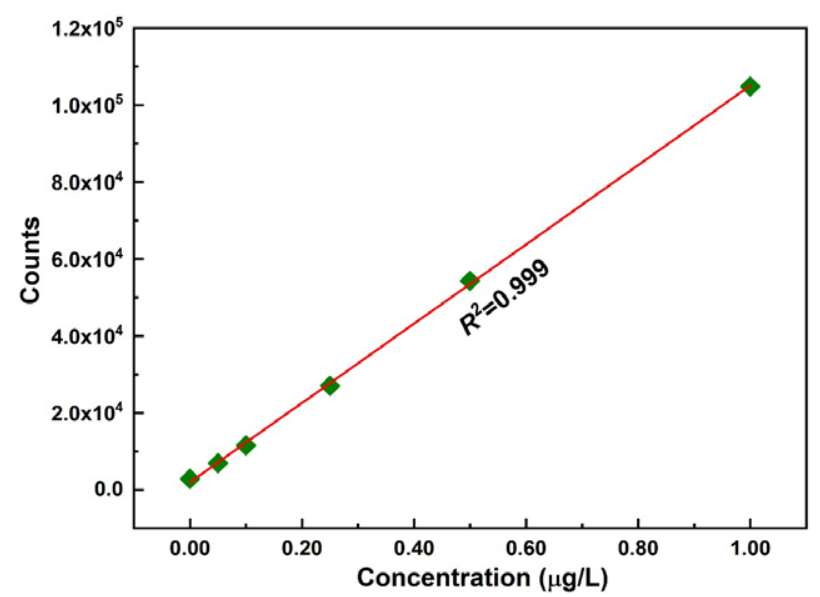

Figure A1. Standard curve of $\mathrm{Pb}$ with a dynamic range of $0.05 \mu \mathrm{g} / \mathrm{L}-1.00 \mu \mathrm{g} / \mathrm{L}$ in the ICP-MS analysis. 
Figure A1 shows the standard curve of $\mathrm{Pb}$ with a dynamic range from $0.05 \mu \mathrm{g} / \mathrm{L}$ to $1.00 \mu \mathrm{g} / \mathrm{L}$ obtained from the ICP-MS analysis. The lowest calibration concentration of $0.05 \mu \mathrm{g} / \mathrm{L}$ was detectable. The linearity of the tested dynamic range (i.e. the lowest calibration concentration of $0.05 \mu \mathrm{g} / \mathrm{L}$ to the highest calibration concentration of 1.00 $\mu \mathrm{g} / \mathrm{L})$ also showed good fits with $R^{2}$ of 0.999 . The high instrumental sensitivity and high linearity of the calibration curve ensured the accuracy of detection (e.g. confidence of at least $99.9 \%$ removal efficiency for an initial $\mathrm{Pb}$ concentration of $200 \mu \mathrm{g} / \mathrm{L}$ could be achieved).

\section{Acknowledgement}

This work is supported by the Dean's Fund for Research Path Exploration from the Faculty of Engineering at The University of Hong Kong (HKU). The Electron Microscope Unit and School of Biological Sciences at HKU are thanked for providing SEM and ICP-MS tests.

\section{Notes on Contributors}

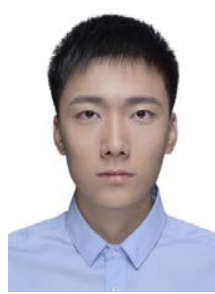

Mr Junwei Zhang is a Year 3 undergraduate student at The University of Hong Kong (HKU). He has a strong research interest in membrane technology and has been working as a student research assistant under the supervision of Dr Hao Guo and Prof Chuyang Tang in The Membrane-based Environmental and Sustainable Technology Lab (MembEST) for almost two years. He has been awarded several scholarships and funds including HKU Foundation Entrance Scholarship, Reaching Out Award, C.V. Starr Scholarship and Dean's Fund for Research Path Exploration.

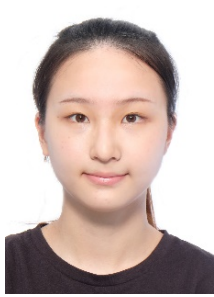

Ms Yan Tung Lo is a Year 4 undergraduate student at HKU, majoring in Civil Engineering and Marketing. Her interest lies within the field of environmental engineering. She is currently working on nanofibrous membranes for water contaminant removal as her final year project. She has also received the Dean's Fund for Research Path Exploration to work as a student research assistant under the supervision of Dr Hao Guo and Prof Chuyang Tang at the Department of Civil Engineering at $\mathrm{HKU}$.

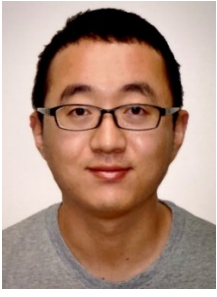

Dr Hao Guo is a Postdoctoral Fellow of the MembEST from Department of Civil Engineering at HKU. He received his B.Eng. degree from Wuhan University of Technology in 2010, M.Eng. degree from Huazhong University of Science \& Technology in 2013, and Ph.D. degree from HKU (supervisor: Prof Chuyang Tang) in 2017. His research mainly focuses on the fundamental mechanism investigation and novel materials development in advanced membrane-based water treatment and seawater desalination for sustainable water production. He is an awardee of 2020 MIT Technology Review's Innovators under 35 (Asia Pacific Region) for his innovative water filter works for disaster relief.

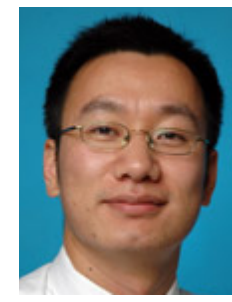

Prof Chuyang Tang is a Professor in Department of Civil Engineering at HKU. He received his Ph.D. degree in Environmental Engineering from Stanford University in 2007. His research interests include membrane technology, desalination, wastewater reclamation, water chemistry, and environmental materials. He is serving as an Editorial Board Member for Environmental Science and Technology Letters, Journal of Membrane Science, and Desalination. He has published 260 journal papers with a total citation of over 16000 and h-index of 71 (Web of Science). He is a recipient of Hong Kong Research Grants Council's Senior Research Fellow Award (2021-2025), The Singapore Ministry for National Development R\&D Merit Award (2013), Finland Distinguished Professor Program Fellow Award (2010), International Desalination Association Fellowship Award (2010), and over 40 Awards of Top Cited Papers, Most Cited Authors, Best Presentations, and Best Posters.

\section{References:}

[1] Ahmed FE, Lalia BS and Hashaikeh R (2015). A review on electrospinning for membrane fabrication: Challenges and applications. Desalination, 356, pp. 15-30.

[2] Aliabadi M, Irani M, Ismaeili J, Piri H and Parnian MJ (2013). Electrospun nanofiber membrane of PEO/ Chitosan for the adsorption of nickel, cadmium, lead and copper ions from aqueous solution. Chemical Engineering Journal, 220, pp. 237-243.

[3] Babel S and Kurniawan TA (2003). Low-cost adsorbents for heavy metals uptake from contaminated water: A review. Journal of Hazardous Materials, 97, pp. 219-243. 
[4] Chowdhury S, Mazumder MAJ, Al-Attas O and Husain T (2016). Heavy metals in drinking water: Occurrences, implications, and future needs in developing countries. Science of The Total Environment, 569-570, pp. 476-488.

[5] Derlon N, Peter-Varbanets M, Scheidegger A, Pronk W and Morgenroth E (2012). Predation influences the structure of biofilm developed on ultrafiltration membranes. Water Research, 46, pp. 3323-3333.

[6] Fane A, Tang C and Wang R (2011). Membrane technology for water: Microfiltration, ultrafiltration, nanofiltration, and reverse osmosis. Treatise on water science, 1, pp.302-335.

[7] Fu F and Wang Q (2011). Removal of heavy metal ions from wastewaters: A review. Journal of Environmental Management, 92, pp. 407-418.

[8] Gonzalez S, Lopez-Roldan R and Cortina JL (2013). Presence of metals in drinking water distribution networks due to pipe material leaching: a review. Toxicological \& Environmental Chemistry, 95, pp. 870-889.

[9] Guo H, Ren Y, Sun X, Xu Y, Li X, Zhang T, Kang J and Liu D (2013). Removal of $\mathrm{Pb} 2+$ from aqueous solutions by a high-efficiency resin. Applied Surface Science, 283, pp. 660-667.

[10] Guo H, Wang J, Han Y, Feng Y, Shih K and Tang CY (2017). Removal of perfluorooctane sulfonate by a gravity-driven membrane: Filtration performance and regeneration behavior. Separation and Purification Technology, 174, pp. 136-144.

[11] HKSAR Government (2015). Lead in drinking water incidents. [Online]. Available at: $<$ https://www.isd. gov.hk/drinkingwater/eng/index.html $>$. [Accessed on 25 March 2020].

[12] Hyder MN, Huang RYM and Chen P (2006). Correlation of physicochemical characteristics with pervaporation performance of poly(vinyl alcohol) membranes. Journal of Membrane Science, 283, pp. 281-290.

[13] Kampalanonwat P and Supaphol P (2010). Preparation and adsorption behavior of aminated electrospun polyacrylonitrile nanofiber mats for heavy metal ion removal. ACS Applied Materials \& Interfaces, 2, pp. 3619-3627.

[14] Kirwan LJ, Fawell PD and VanBronswijk W (2003). In situ FTIR-ATR examination of poly(acrylic acid) adsorbed onto hematite at low pH. Langmuir, 19, pp. 5802-5807.

[15] Li N and Bai R (2006). Highly enhanced adsorption of lead ions on chitosan granules functionalized with poly(acrylic acid). Industrial \& Engineering Chemistry Research, 45, pp. 7897-7904.

[16] Liu Y, Yan J, Yuan D, Li Q and Wu X (2013). The study of lead removal from aqueous solution using an electrochemical method with a stainless steel net electrode coated with single wall carbon nanotubes. Chemical Engineering Journal, 218, pp. 81-88.
[17] Mansur HS, Sadahira CM, Souza AN and Mansur AAP (2008). FTIR spectroscopy characterization of poly (vinyl alcohol) hydrogel with different hydrolysis degree and chemically crosslinked with glutaraldehyde. Materials Science and Engineering: C, 28, pp. 539-548.

[18] Matlock MM, Howerton BS and Atwood DA (2002). Chemical Precipitation of Lead from Lead Battery Recycling Plant Wastewater. Industrial \& Engineering Chemistry Research, 41, pp. 1579-1582.

[19] Mehdipour S, Vatanpour V and Kariminia HR (2015). Influence of ion interaction on lead removal by a polyamide nanofiltration membrane. Desalination, 362, pp. 84-92.

[20] Oka PA, Khadem N and Bérubé PR (2017). Operation of passive membrane systems for drinking water treatment. Water Research, 115, pp. 287-296.

[21] Papanikolaou NC, Hatzidaki EG, Belivanis S, Tzanakakis GN and Tsatsakis AM (2005). Lead toxicity update. A brief review. Medical science monitor, 11, pp. RA329-RA336.

[22] Peter-Varbanets M, Hammes F, Vital M and Pronk W (2010). Stabilization of flux during dead-end ultra-low pressure ultrafiltration. Water Research, 44, pp.36073616.

[23] Pronk W, Ding A, Morgenroth E, Derlon N, Desmond P, Burkhardt M, Wu B and Fane AG (2019). Gravitydriven membrane filtration for water and wastewater treatment: A review. Water Research, 149, pp. 553565.

[24] Wang J, Guo H, Yang Z, Mei Y and Tang CY (2017a). Gravity-driven catalytic nanofibrous membranes prepared using a green template. Journal of Membrane Science, 525, pp. 298-303.

[25] Wang J, Wu Y, Yang Z, Guo H, Cao B and Tang CY (2017b). A novel gravity-driven nanofibrous membrane for point-of-use water disinfection: polydopamine-induced in situ silver incorporation. Scientific Reports, 7, pp. 2334.

[26] Wang X and Hsiao BS (2016). Electrospun nanofiber membranes. Current Opinion in Chemical Engineering, 12, pp. 62-81.

[27] World Health Organisation (2011). Guidelines for drinking-water quality (4). Geneva: World Health Organisation, pp. 383.

[28] World Health Organisation (2019). Drinking Water. Available at: $<$ https://www.who.int/en/news-room/ fact-sheets/detail/drinking-water $>$. [Accessed on 25 March 2020]. 